\title{
Editorial
}

\section{What we should be saying - and doing - about undernutrition}

'Evils once recognised are half-way on towards their remedy'. This was Elizabeth Gaskell's creed, written in a letter to a friend. She was explaining why in her novels she exposed the dreadful conditions of the impoverished working classes - women and children most of all - in Manchester in the mid-19th century. Let us hope she is right.

\section{Skyscraper or old tin shack?}

Laborious... duplicative... weak... grossly insufficient... poorly targeted... fragmented... dysfunctional. These are judgements of the 'global architecture' designed and built to stem world undernutrition. Some architecture! These scorching words are contained in the invited commentary by one of our associate editors, Ricardo Uauy, published in this issue ${ }^{(1)}$. The judgements are not personal. He is co-author of the culminating paper of a series of five on the theme of maternal and child undernutrition, published earlier this year in Lancet $^{(2)}$. In turn, this series is the fruit of a series of consultations involving scores of experts, with support from the World Bank and the Gates Foundation.

We also publish a letter by John Waterlow ${ }^{(3)}$, whose work on behalf of undernourished children in the tropics began in 1945. The politics of undernutrition is also touched upon in this month's Out of the Box column ${ }^{(4)}$. In pointing out that our profession is neglecting the wretched of the earth, John Waterlow and Ricardo Uauy both issue this journal a challenge.

We stand challenged. Yes, they are right. Public Health Nutrition does not carry a proper share of articles on undernutrition. We on the editorial board can immediately do two things about this. One is to ensure that our editorial pages, which include editorials such as this, our Out of the Box column, invited commentaries and the letters pages are better balanced. The other is to urge researchers committed to finding solutions to undernutrition to submit original papers.

In the Lancet paper and in his commentary, Ricardo Uauy and his colleagues propose that 'The editors of academic journals with an interest in maternal and child undernutrition should meet in 2008, to develop a strategy to increase the profile and programmatic relevance of the topic and to reduce fragmentation'. There are 417 such journals and getting all to work together will be a challenge; this journal pledges to do better.

\section{Words - and action}

But for a journal, doing means words. What is most needed is action. And here it seems to me, as a public health nutritionist who spends a lot of time working in Africa and India, that as a profession we have a problem, and may even be part of the problem. Our dilemma is expressed by 'The development set', a doggerel poem by the missionary and world hunger specialist Ross Coggins ${ }^{(5)}$. One verse is

We discuss malnutrition over steaks

And plan hunger talks during coffee breaks,

Whether Asian floods or African drought,

We face each issue with an open mouth.

Perhaps our task should be limited to helping to make the world a place within which it is easier for impoverished communities to feed themselves, as John Waterlow suggests in his commendation of leaf concentrate produced by villagers on their own behalf and that of neighbouring communities. But this may engage us more as citizens than as nutritionists.

\section{The politics of hunger}

Surely also it is impossible to see why undernutition persists in the world unless a bigger picture is discerned. This includes international trade and aid used by rich countries as an extension of their foreign policies. The amount of aid of all forms that goes to impoverished countries is a fraction of the interest paid by those countries to service their foreign debt.

John Waterlow uses the word 'controversial' in the context of undernutrition as a global public health issue. The original fundamental reason why tens of millions of families especially in Asia and Africa are now famished is exploitation by the colonial powers. It may be uncomfortable to point out that this is not just history. Indeed, tens of thousands of mothers and children in Afghanistan and Iraq now are beyond anybody's help. They have died as a result of invasions and insurgencies, as have hundreds of thousands of mothers and children in African countries reduced to chaos and famine by incessant wars and massacres. We may have different views on the 
foreign policies of the world's most materially rich countries. But we surely all agree that the impact of these policies, as practised on many of the world's most impoverished countries, is catastrophic.

This has been understood in the USA at the highest level. Dwight Eisenhower is the most recent US President who was a senior wartime officer. After he left the US army he reflected on the horrors of war. In his first public address after his election, on 16 April 1953, he spoke about the fundamental reasons for undernutrition. He said:

Every gun that is made, every warship launched, every rocket fired signifies in the final sense, a theft from those who hunger and are not fed, those who are cold and are not clothed... This world in arms is not spending money alone. It is spending the sweat of its laborers, the genius of its scientists, the hopes of its children.

This journal and this profession does not have the answers to undernutrition. But at least we have the responsibility to see and acknowledge the scale of the problems. This is a time to bear Elizabeth Gaskell's essential optimistic belief in mind.

Barrie Margetts

Deputy Editor

\section{References}

1. Uauy R (2008) Undernutrition is undernourished. Public Health Nutr 11, 647-649.

2. Morris S, Cogill B \& Uauy R (2008) Effective international action against undernutrition: why has it proven so difficult and what can be done to accelerate progress? Lancet $\mathbf{3 7 1}$, 608-621.

3. Waterlow J (2008) Undernutrition should be the first priority. Public Health Nutr 11, 651

4. Cannon G (2008) Out of the Box. Public Health Nutr 11 , 550-553.

5. Coggins R (1978) The development set. J Communications 28, 80 .

6. Eisenhower D (1953) The chance for peace. Address to the American Society of Newspaper Editors, 16 April. http:// www.quotedb.com/speeches/chance-for-peace (accessed March 2008).

\section{In this issue}

Monitoring and surveillance of population dietary trends, determinants of dietary intake and related nutritional status are central to public health nutrition as a discipline. In this issue, a number of papers have relevance to this aspect of public health nutrition practice and research.

Compliance with recommendations is a common theme running through this issue. Seck and Jackson ${ }^{(1)}$ report on a study exploring the determinants of compliance with $\mathrm{Fe}$ supplementation among pregnant women in Senegal. Their findings reinforce the importance of clear guidance about supplement intake and education about the benefits of compliance with supplement prescriptions.

Still on the issue of micronutrient deficiencies, Ma et $a l^{(2)}$ report on a study in China exploring the feasibility and cost-effectiveness of strategies to address the significant public health issue of $\mathrm{Fe}$ and $\mathrm{Zn}$ deficiencies. Using the standard WHO Ingredients approach, they have estimated the costs and cost-effectiveness of supplementation, food diversification and food fortification.

Dietary variety is a key determinant of micronutrient status in many populations. Pedro et al $^{(3)}$ present the results and analysis of a study of total food items recorded in a longitudinal group of urban black South African children from the Birth-to-Twenty Study at five interceptions at ages 5, 7, 9, 10 and 13 years, respectively.

Romaguera et al. ${ }^{(4)}$ report on the nutritional status of two Andean populations in Argentina using a crosssectional study using anthropometric measures. Their data suggest these populations are in the early stages of nutritional transition, with evidence of undernutrition and overnutrition coexisting at the population level.

Two papers in this issue specifically address the challenges associated with validity measurements, analysis and interpretation in public health nutrition research. Barclay et $a l^{(5)}$ assess the ability of an FFQ to rank Australians according to their intake of total carbohydrate, sugar, starch, fibre, glycaemic index and glycaemic load, using a cross-sectional sample of 2868 older Australian adults. Huybregts et $a l^{(6)}$ present a study providing evidence that food photographs can be a valuable tool for the quantification of food portion size on a group level.

The sometimes pernicious influence of food marketing targeting the young is of considerable interest to readers of this journal. Jones and Fabrianesi ${ }^{(7)}$ report on a study using intercept interviews to investigate parents' perceptions of branded snack foods targeted at children, and the extent to 